\title{
Protection and Brand Construction of Wheat Straw Craft Painting as Intangible Cultural Heritage in Heilongjiang
}

\author{
Xue Jiang \\ School of Art Design \\ Harbin University of Commerce \\ Harbin, China
}

\begin{abstract}
The paper has organically combined the internal resources and external environment of Harbin wheat straw craft painting culture with its brand development strategies, comprehensively analyzed the influencing factors and discussed the feasible development way of Harbin wheat straw painting culture brand.
\end{abstract}

Keywords-The Belt and Road; brand building; brand communication

\section{INTRODUCTION}

China is in a key transition period in history. Under the background of economic globalization and national modernization, folk art is facing a unprecedented unknown impact. Its living environment has changed rapidly and profoundly. To re-seek the positioning of folk art in modern life is the need of social development. On December 3, 2014, the State Ministry of Culture issued a notice that Harbin straw painting was listed as a national intangible cultural heritage, which has enabled us to meet the folk art with the strong northeast characteristics.

\section{THE INTANGIBLE CUltURAl HERITAGE IN HEILONGJIANG - A SURVEY OF HARBIN STRAW CRAFT PAINTING}

In 2015, Harbin's cultural industry bucked up and realized an industrial added value of 27 billion yuan, accounting for $6.4 \%$ of GDP. It became a new growth and a pillar industry in the national economy. The formation of a rich and prosperous folk art and tourism souvenir market effectively promotes the province's tourism prosperity and development, promote tourism and cultural quality, and thus forming new cultural tourism landscape.

Straw wheat craft painting, also known as straw craft painting, has become an intangible cultural heritage. It has a history of two thousand years in China and a history of more than 100 years in Harbin. After decades of improvement of the production process, it has developed into dozens of series, including landscapes, flowers and birds, characters, animals,

The paper is sponsored by 2017 Heilongjiang Provincial Philosophy and Social Sciences Research and Planning Project. antique articles and buildings. There are more than 50 varieties and 2000 colors. It is known as "one masterpiece in the folk". It has been exported to other countries. It has been listed as outstanding craft emblem product by the UNESCO and an intangible cultural heritage in Heilongjiang. Straw painting has enjoyed a high reputation at home and abroad. It has won prizes in the World Expo for many times, and the Hundred Flowers Awards in Arts and Crafts for several consecutive years from 1981. In 1982, Hongkong Ta Kung Pao specially made a report on the development and characteristics of Harbin wheat straw craft painting. As a national intangible cultural heritage and key cultural craft of the Ministry of Culture, Harbin straw craft painting will focus on innovation and creativity, so that traditional industries and formats can gain a higher industrial value.

Only a few books and literature materials have involved the study of this field. The researches of relevant papers mostly are shallow. For example, Li Li's Henan Straw Wheat Painting Art, Zhang Min and Cui Xiaojing's Development Opportunities of Puyang Straw Painting and National Technique mainly researched the craftsmanship of straw painting in Henan Puyang and its aesthetic value and commercialized development. Gong Lihui's Inherited Development and Artistic Value of Liaoning Straw Wheat Painting mainly researched the social value and artistic value of straw painting in the Western Liaoning. The Chinese Traditional Arts and Crafts - Analysis on Aesthetic Value of Straw Painting mainly analyzed the aesthetic characteristics and existing forms of straw painting from the perspective of arts and crafts. The Gorgeous and Simple Harbin Straw Painting and Ding Ru's Li Youshu: Lighting a Wisp of Firework in Straw Painting, Wang Mei's Carrying Forward Folk Arts and Loving Occupation Education - Interview Record of Liu Yongming, Inheritor of Fangfeng Straw Painting, A Sang's Straw Painting Recorded into the World Guinness Record - Chinese Folk Artist Shen Sheguo and Weng Rui and Xu Cheng's Exquisite, Elegant and Wonderful - Review on Gan Xinliang's Straw Painting and other papers are introductions to some representative works and interviews to straw painting inheritors in our country.

At present, the researches upon the art of straw painting in our country mainly focus on the theoretical discussion and the introduction of the famous artists and are mainly about the 
aesthetics of the straw painting and the inheritance and protection measures. There is little research about brand construction of Harbin wheat straw painting and its integrated development with other disciplines, such as, communication and big data processing technology.

\section{THE BRAND DEVELOPMENT OF HARBIN STRAW CRAFT PAINTING}

The interaction principle in the interdisciplinary sociology is introduced in the protection of Harbin wheat straw painting, which has made a breakthrough out of the one-way protection. It can provide new ideas, new goals, new development for the protection of the Harbin straw painting to use the development of related disciplines. We can use multiple channels, and Lasswell's "5W" mode in communication to promote the cultural brand communication of Harbin straw painting. We can make full use of the mass media and the new media to improve the dissemination of cultural brand and increase the scope of the audience, to promote the formation of hot social culture and extend the value chain of brand culture. It is a exploration from the perspective of the theoretical research, and this new exploration can provide more ideas for the protection of the intangible cultural heritage and the development of cultural brand in the later. It can promote cultural exchanges and innovations among nations and enhance national cohesion to deeply integrate the strategy of "The Belt and Road". And cultural exchanges can drive the development of economy.

Intangible cultural heritage - Harbin straw craft painting. Harbin straw craft paintings have distinctive national characteristics and strong local characteristics. Their works can show the unique personality and aesthetic consciousness of the people of Heilongjiang. We can appreciate the practical and ornamental features, historical and national culture, festival folk custom and cultural blending in Harbin straw craft painting. It has a distinctive artistic style. Harbin straw painting has formed a natural, fresh, simple and honest artistic characteristic in selection of materials, use of techniques, color matching and process procedures in addition to its traditional and innovative techniques. Its artistic language and cultural inheritance is a kind of artistic and aesthetic value of folk craftsmen and art lovers formed spontaneously in production and labor, and of a unique art style. Its artistic language and style is very typical, and its design and composition idea is relatively mature, forming a regional representative language symbol.

Heilongjiang is a big ecological tourism province in the northern China. China constantly promotes "The Belt and Road". We should deeply integrate with the strategy of "The Belt and Road" and actively participate in the construction of "Economic Corridor among Mongolia, Russia and China". With the increasingly frequent economic and trade activities between China and countries in Asia, Africa and Latin America, and the deepening of business activities, we have enhanced exchanges of cultural fields with countries in Asia, Africa and Latin America. The intangible cultural heritage in Heilongjiang, wheat straw craft painting can coagulate the essence of national culture, promote cultural exchange and innovation among ethnic groups and enhance national cohesion.

The protection of Harbin straw art painting should not only proceed from its excellent connotation, but also depend on the actual situation of the development of Heilongjiang culture and rely on the strength of the government, the market and the people. We should protect and nurture the cultural and ecological environment of crafts for it can provide a steady stream of forces. We should change our past artistic value only concept and accept its economic value, because it can provide assignable role in the protection of Harbin straw painting. We should also guide the establishment of a good model of economic development and create considerable interest incomes for the local people, so as to form a common development of cultural and economic situation. In the rational and orderly development of cultural resources, we can protect our cultural ecology, carry forward our national culture and retain a bright light for Chinese outstanding traditional handicraft culture.

The wheat straw painting is Harbin's regional representative language symbol. We can integrate its systematic development and design and the construction of brand culture into the construction of the famous ice and snow city. It can promote the protection and inheritance of straw painting and the development of the ice and snow tourism city. It can help develop the cultural connotation of Harbin straw craft painting to introduce it into tourism development and thus gain more protection funds and development power. The protection of straw craft painting can promote the further mining of its cultural value and the realization of its economic value and social value. Thus, promote the grade of tourism product and item. Finally, form a positive interaction between the protection and tourism development.

It needs to study the practical, cultural and innovative aspect of Harbin wheat straw painting in order to develop and construct the brand of Harbin wheat straw painting. We can discuss how to recombine the spiritual element of Harbin wheat straw painting with modern language and give it new characteristics of the times and enrich its practical value and thought connotation, and expand a broad development prospect.

It can be the foundation of cultural brand construction of Harbin wheat straw craft painting to carry forward the blacksoil culture and ethnic culture and customs of Heilongjiang, form the advantages of industry chain and industrial cluster and promote the development of Heilongjiang arts and crafts industry. 


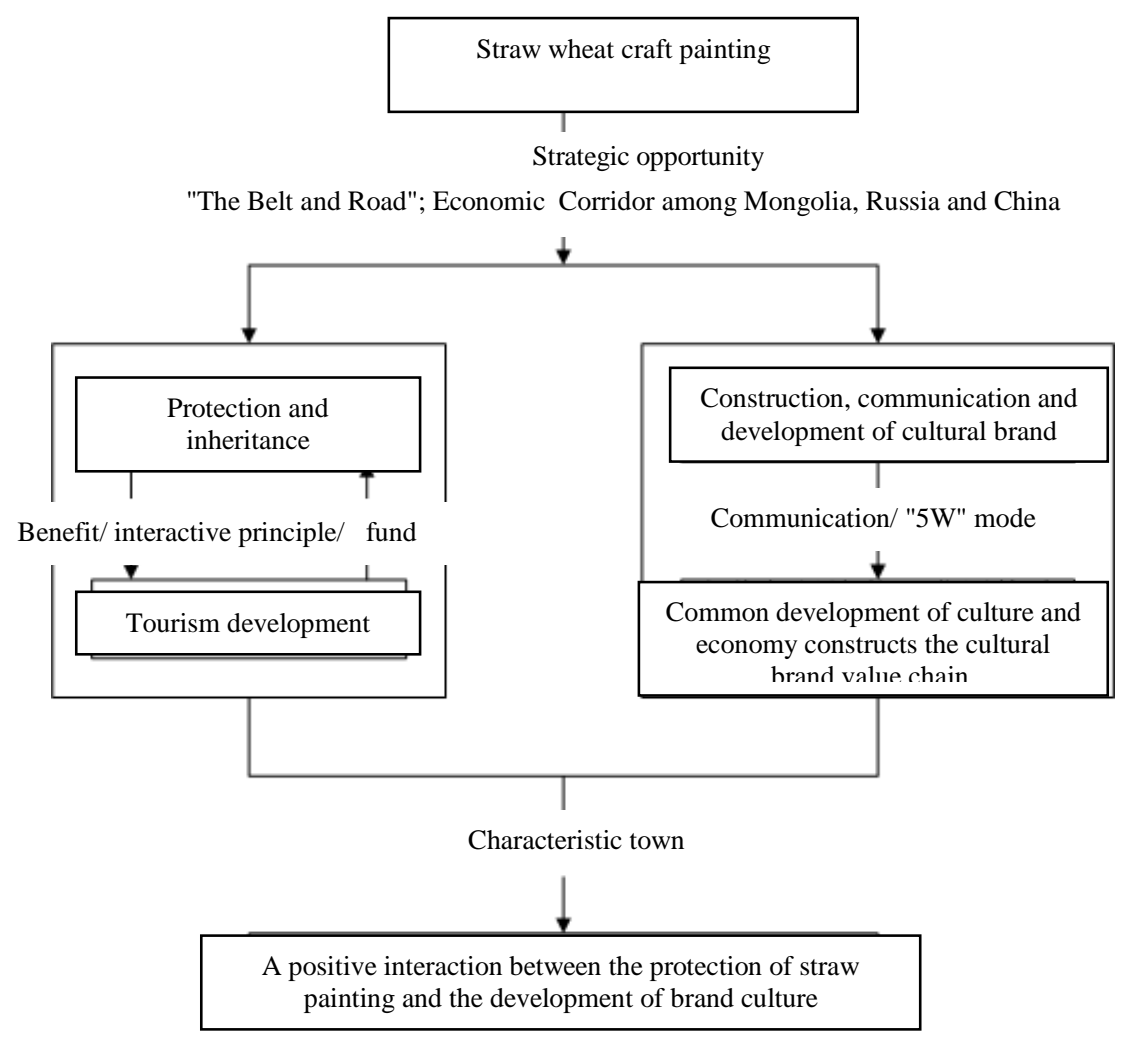

\section{CONCRETE MEASURES FOR BRAND BUILDING OF HARBIN STRAW CRAFT PAINTING}

\section{A. Protection Research}

The protection and inheritance of an art culture is determined by its own cultural connotation value and people's attention degree, propaganda and promotion force and protection consciousness. Under the background of economic globalization and diversification, the traditional national culture faces the dual tasks of protection and development. Heilongjiang wheat straw craft painting is no exception. To tap cultural resources and build cultural brands, the primary task is to further collect, sort out and summarize existing materials and record and preserve them with modern scientific and technological means. We should maintain and promote the development of the cultural brand of wheat straw painting, and ensure its continuity and inheritance in the modern society and keep the original character of its cultural connotations. Nowadays, with the changes of tradition to forms of modern times, irresistible changes have taken place in the connotation and extension of national culture, which needs to be studied by anthropology, folklore and other related subjects.

\section{B. Cultural Brand Construction}

Harbin straw painting stresses the mining of the cultural connotation and shaping of brand image characteristics. Takes regional and folk characteristics as creative idea and uses visual symbol with traditional local art characteristic to evoke people's emotional and cultural resonance, which is the embodiment of the concept of cultural brand.

\section{Cultural Brand Image Features}

Craft, as a bearing object to a particular culture, is materialized in the expression and reflection of its culture. The cultural connotation is expressed through tangible material form. The art's materialized form is an effective way of cultural cognition and communication. So, we should integrate the cultural brand of Harbin straw painting into the construction system of its ice and snow city. The development path of the ice and snow tourism city should be started from the cultural industry and tourism environment, and develop the strategy of taking Harbin straw painting as tourism craft, which is important to cultural inheritance and application.

\section{The Promotion and Development of Brand Culture}

We can improve the reputation of Harbin wheat straw painting as Harbin's characteristic tourism craft, and enlarge its market share, establish its local characteristics, enhance brand 
value, attract consumers with its distinctive cultural character and provide strong support for Harbin ice and snow tourist development.

This paper analyzes the receivers' category, age structure and best selling style of Harbin straw art paintings, and provides the data technical basis for the development and research of Harbin straw art paintings. At the same time, it combines big data technology and cultural and art resources platform to make it possible for cultural communicators to quantify the details of public demand, access to behavior, appreciation of emotions and cultural resources.

Use multi-channels, and make full use of the mass media and the new media to improve the dissemination of culture and broaden the cultural brand of Heilongjiang wheat straw painting. Brand promotion should be carried out through various channels and in various ways, by comprehensive use of various means of communication, such as books, text, pictures, audio, video and other organic combination. Introduce Lasswell's "5W" mode in communication, and based on the "5W mode", further promote the cultural brand communication of Harbin straw painting process. Make full use of the mass media and the new media to improve the dissemination of cultural brand and increase the scope of the receiver, promote the formation of the hot social culture and extend the value chain of culture brand.

Break through the traditional one-way design concept and introduce the interaction principle. According to the interaction principle, under the force of leading role, protect the factor and tourism development factor. Through imaginative rehearsal, strengthen guidance and understanding of role, and form the interaction process. In this process protection factor and tourism development factor have changed, and thus promote the object of their acting forces - the intangible cultural heritage. Then drive the development of related culture and economic structure, and effectively provide new ideas for the development of Harbin wheat straw painting.

Combined with the cultivation of characteristic towns throughout the country proposed by the Ministry of Housing and the National Development and Reform Commission in July 2016, it is decided to introduce the intangible cultural heritage Harbin wheat straw painting into the construction of state-level characteristic pilot town by the form of experience museum - Harbin Songbei Maple Leaf Town. It is regarded as a characteristic cultural tourism site combing leisure shopping, cultural tourism, ice and snow recreation, characteristic agriculture and ecological endowment. It can promote the cultural industry agglomeration, innovation and upgrading with new idea, new mechanism and new carrier.

\section{CONCLUSION}

Under the background of economic globalization and diversification, the traditional national culture faces the dual tasks of protection and development. The intangible cultural heritage in Heilongjiang, wheat straw craft painting is no exception. Therefore, it is urgent to strengthen the protection of the brand and outstanding artists, enhance brand awareness, strengthen the management of intellectual property, to take protective measures for the traditional and newly developed varieties in the inheritance and brand development of Harbin straw craft painting.

\section{REFERENCES}

[1] Liu Yang. Research on Wheat Straw Craft in Heilongjiang. Harbin Normal University. Jun. 1, 2013.

[2] Liu Chen. Chinese Traditional Arts and Crafts - Analysis on Aesthetic Value of Straw Painting. Public Art. Oct. 25, 2011.

[3] Gao Qiujuan \& Zhao Gang. Gorgeous and Simple Harbin Straw Painting Heilongjiang Pictorial.

[4] Xiao Yanzeng. Interactive Study on the Protection of Intangible Cultural Heritage and Tourism Development. Hunan Normal University, May 2006.

[5] Geng Guanglian. Research on the Protection of Intangible Cultural Heritage in China. University of Technology. June. 9, 2014.

[6] Wang Yao. Cultural Industry Development Path in Heilongiiang under the Background of "The Belt and Road" Strategy. Feb. 2015. 